\title{
SCHOOL ATTENDANCE AND CHILDREN'S BIORYTHMS. SECONDARY SCHOOL STUDENTS' PERCEPTION ABOUT THEIR SCHOOL TIME, AND OUT - OF SCHOOL TIME AND ITS RELATION TO SCHOOL ATTENDANCE
}

\author{
Notopoulou Vasiliki'i, \\ Giaouri Stergiani ${ }^{2}$ \\ ${ }^{1}$ Biologist, $\mathrm{PhD}$, \\ Headmaster in the Secondary School of Xyrolimni, \\ Kozani, Greece \\ ${ }^{2}$ Assistant Professor of School Psychology, \\ University of Western Macedonia, \\ Greece
}

\begin{abstract}
:
In recent decades, there has been a strong interest in the relation between the biorhythms and school attendance. It is a fact that school attendance, and therefore school time, can largely determine students' daily life, their biological functions, and their learning processes. The aim of this work is to investigate the relationship between students' biorhythms and their school performance. More specifically, the research focuses on students' perceptions of their time, school and non-school, as well as, how time is associated with school attendance. More particularly, emphasis is placed on students' time in extracurricular activities and how this time relates to their performance in school life. It explores students' perceptions of various activities they can develop during their school time, as well as the emotions they experience while participating in the school program. The research sample consists of students attending schools of the Secondary Education of the Prefecture of Kozani. Specifically, students from A', B', C' Gymnasium and A' Lyceum participated in the research (252 students in total). A written structure questionnaire was selected as a tool for data collection, which included closed-ended questions and it was completed individually by the students. The questionnaire included 22 questions. The statistical processing of the collected data was done with the SPSS statistical program and led to the finding that students prefer to manage a part of their school time on their own and that non-school time helps them acquire new knowledge with pleasure. They believe that the lessons should be alternated with practical activities and they do not prefer the school time to last 90 minutes. Additionally, they do not think that their performance in mathematics and language is better in the first hours. The thematic axes of the questionnaire are the following: a) the time in the daily life of the
\end{abstract}

i Correspondence: email vasonot@hotmail.com 
students, b) the wishes of the students in relation to the school time, c) the time in the school and the daily life of the students, d) the time in the school and activities within the school. The results of the research lead to the finding that students prefer the activities they do outside of school because they are more enjoyable for them, since they have chosen them. The activities that students do outside of school come from the personal choices of students, while the activities that students have outside of school have better performance in school activities. There is a positive correlation between school performance and math and language lessons, as students believe that in the early morning hours they can perform better in math and language.

Keywords: bioregulation, extracurricular activities, school time, school attendance

\section{Introduction}

In recent decades, there has been a strong interest in the relation between the biorhythms and school attendance. It is a fact that school attendance, and therefore, school time, can largely determine students' daily life, their biological functions, and their learning processes.

Biorhythm is related to natural processes of organisms, which display periodicity according to daily, weekly, monthly and yearly environmental changes (Fontana, Copetti, Mazzoccoli, Kypraios, \& Pellegrini, 2012). It is divided in three categories; daily (circadian rhythm), which lasts approximately twenty-four hours, as long as an entire day, weekly rhythm, which lasts approximately a week (circaseptan rhythm), monthly rhythm, which lasts approximately a month - 28 days (circalunar / circamensal rhythm), and, lastly, the yearly rhythm which lasts for a year (circa-annual rhythm) (Shephard, 1984). The biological clock as a biological process with periodic change during a 24-hour period, is related to the circadian rhythm and it was developed in order to provide organisms the ability to adjust to the environmental changes (Rapti as cited in Kassaveti, 2019). Especially for humans, the centre of the biological clock is in the hypothalamus, which also determines the regulation of the circadian changes of the body's temperature. This finding, along with the assumption of humans' ability to understand and be aware of time intervals, indicate that humans' internal time is regulated on a biological basis (Eisler \& Eisler, 1992).

Kerkhof (1985) mentions that there are different categories of humans who follow two types of biorhythms (chronotypes) and, thus, there are morning people (early-risers) and night people (night owls). There is an intermediate category, as well, the intermediate types, who appear to perform better in the afternoon and represent the largest category. Morning people tend to feel tired earlier at night and wake up early in the morning, while night people appear to sleep later at night and wake up with difficulty in the morning (Jone et al., 2017; Wittmann, Dinich, Merrow, \& Roenneberg, 2006). According to Jones et 
al. (2017), the definition of chronotype is connected to genetic activity and has a genetic basis.

Neurobiology explains the presence of biorhythms, focusing significantly on the conciseness of the circadian rhythm hormones, which are mainly melatonin and cortisol. Melatonin is predominantly increased during sleep in early morning hours, while cortisol is increased after the morning awakening and during noon. Melatonin is considered to contribute to the organism's adjustment to the light-dark cycle of the environment. There are also indications that it contributes to the regulation of the biological rhythms. This hormone affects the hormonal function of the anterior and posterior hypophysis of the brain, resulting to restful sleep state. The use of melatonin contributes to redefining the biological rhythms, when they are disrupted (Bailey \& Heitkemper, 2001).

The above findings are directly related to students' lives, as chronotype is characteristic to each person, constituting a specific indicator of life and changes according to age. As teenagers begin to sleep later, while schools impose the beginning of classes early, students who are unable to adjust their circadian rhythm in these circumstances, face issues (Milic et al., 2014). Several researchers also point out that the static organizational structure of school time with a strict time distribution and schedule negatively affect the quality of education, as the provided school curriculum often remains incomplete. Additionally, students do not have the required time to deepen the acquisition of new knowledge and teachers are not always able to provide the required time to resolve the students' questions aiming at knowledge acquisition (Husti, 1992; Hargreaves, 1997).

\section{Literature Review}

The beginning of the school year in September, the intermediate evaluation throughout the year and the summer holidays after the end of the school year, lasting 8-12 weeks, are present on all levels of education, in all European countries' curricula. Research by the Pedagogical Institute (2003) showed that secondary-education students in Greece have classes 185 days per year, including exam periods. In developed countries, respectively, students attend classes 188 days per year, on average. The same study presents the teaching hours per week, when secondary-education students in Greece have classes 35 hours per week, while the average of the other countries does not exceed 29 hours per week. The educational time, however, constitutes a simplistic means for the evaluation of educators and students' productivity (Pedagogical Institute, 2003). According to Walberg and Tsai (1983), school attendance and performance are complex and possess multiple meanings. For this reason, students' ability to participate and succeed is related to lack of problems on the students' part, and to the achievement of high school performance, according to Kupersmidt and Coie (1990). In their study, Joyner and Molina (2012) observed that their students display lower performances in international competitions, however, as concluded in their research, this is related to the educational 
time dedicated to students in comparison to other countries that display significantly greater results in these competitions.

In a similar study conducted by Colclough and Crosier (2014), the results of PISA Math competition were compared and indicated that in countries where mathematics is taught, there is no linear relationship between the teaching time provided in each country and the competition success. It can be observed from the above, that the success of teaching a module is not defined merely by the quantity of time provided. There are several factors that are responsible for the quality of educational work and, therefore, learning. More specifically, the educational practices applied by the teacher in class, the curriculum provided in each educational level, and the overall educational philosophy play an important role in learning (Joyner \& Molina, 2012).

The choice of the idea of "flexible time" would benefit the students' school performance (Sofou, 2002). "Flexible time" is achieved through the implementation of flexible hours which will be adjusted to "the curriculum and the teaching practice, as well as the educational needs of the students (Sofou, 2002). Kolovos (2004) indicates that several activities may contribute to the attempt to make school time more flexible, such as the implementation of additional hours dedicated to arts and sports, as well as flexiblezone or research programs.

According to Margin (as cited in Kolovos, 2004), students' school time is related to the biorhythms they display. Children's biorhythms, metabolic, biochemical and hormonal are quite different than those of adults. Children, however, are forced to follow the adults' rhythms in school. According to Kolovos (2004), students' performance decreases between 11:00 to 11:30am before it is minimized by 2:00pm. During the rest of the day, biorhythms begin to increase, while they reach their highest level for the second time by 8:00pm. This, however, creates issues to the schools' curricula and the way they run in Greece, as children are exhausted for most of the day.

According to almost all diagnostic tests in the field of Neurobiology, lack of sleep and, therefore, the disorder in the normal functioning of biorhythms, is connected to a number of danger factors for young people (Randler \& Vollmer, 2013). For instance: poor performance resulting to low grades, conflict with family, friends and other students at school, and increased stress. In addition, depression, metabolism disorders, obesity, traffic accidents and weakening of the immune system. Lastly, an increased consumption of caffeine and smoke is observed (Randler \& Vollmer, 2013).

An attempt by several countries is being made to institutionalize the beginning of classes later in the morning. The beginning of school classes at 9:00 appears to be ideal for students who prefer to sleep quite late at night, and these students constitute $92 \%$ (Randler \& Vollmer, 2013). Specifically, in European countries, such as Germany, school usually begins at 7:15 - 8:15. In France and Italy at 8:30, in Spain and the United Kingdom school begins later, at 9:00. In Berlin, secondary schools usually begin classes at 8:00, and in Luxemburg, has 8:35 as start time, something quite pleasant for the students. 
According to Gross (2014), teenagers have a biological need for more sleep, in comparison to adults, as they are still going through their physical development. Wahlstrom (2014) observes decreased hours of sleep in teenagers and considers social reasons, the use of new technologies, increased amount of light and the consumption of caffeine-containing liquids as causes. Research has proven that the shift of early morning classes to later hours, results to additional hours of sleep, and thus, teenagers attend school well-rested. This improves the mental (learning, concentration, memory, etc.), social (class integration, collaboration, etc.) and psychological (emotional balance and behavior control) functions of the teenager - student, a fact that, eventually, benefits their performance improvement (Gross, 2014; Wahlstrom, 2014). Certainly, the shift in the start time of morning classes results to a number of issues. The fact that the educational system is adapted to begin and finish at a particular time, obstructs such a change, which will bring further difficulties. Students' transportation to school classes, parents' long hours of work, students' extracurricular activities are adjusted to the given school curriculum and any change would cause several issues (Wahlstrom, 2014).

However, research conducted by the University of Osijek has shown that students who begin school classes early in the morning do not display a significant difference in drowsiness during the day, compared to those who begin school later (Milic et al., 2014). Dissimilarities were also observed in chronotypes among different student groups, regarding age and gender. Students who went to school earlier displayed greater school success. In conclusion, this study shows that several students who begin school earlier, have adapted to the school's start time. The aim of this study was to define whether the differences in the school's start time affect the students' chronotype, school success or drowsiness during the day. A total of 1020 students from four secondary schools in Osijek, Croatia participated. Students had alternating school shifts (school start times at $7 \mathrm{am}$ or $1 \mathrm{pm}$ and $8 \mathrm{am}$ or $2 \mathrm{pm}$ respectively, biweekly).

Neuroscientists have provided significant findings regarding the learning process, during which the human brain plays an important role, and the presence of biorhythms, in which the hormones melatonin and cortisol play an important role. Melatonin is mainly increased during sleep in the first morning hours, while in contrast, cortisol is mostly increased after the morning awakening and during noon, and it contributes to the regulation of biorhythms (Kostoglou, 2013).

The aim of the present paper is to investigate the students' perceptions regarding the way they experience their school and non-school time. Additionally, data is presented regarding the connection of time during and outside of school with the biorhythms, and more broadly, the biological functions of children, as well as learning. 


\section{Material and Methods}

\subsection{Participants}

Students from West Macedonia and, specifically, Kozani, participated in the present research. In particular, $\mathrm{A}^{\prime}, \mathrm{B}^{\prime}$ and $\mathrm{C}^{\prime}$ grade Gymnasium students took part in this study, while $A^{\prime}$ grade Lyceum students also participated. Among the students, $32.9 \%(83)$ is in the first grade of Gymnasium, 13.5\% (34) is in the second grade of Gymnasium, 42.5\% (107) in the third grade of Gymnasium and $11.1 \%$ (28) in the first grade of Lyceum. Males constitute $49.2 \%$ (124), while females constitute 50.8\% (128). Regarding the educational level of parents, three categories have been formed according to their education. The lowlevel category includes parents who have primary and secondary school education, the intermediate-level category includes parents with high school education, while the highlevel category includes those who have Higher Education degrees. Specifically, the educational levels of fathers were reported to be at $47.6 \%$ (120) of intermediate educational level, $27 \%$ (68) of high educational level, while $25.4 \%$ (64) of low educational level. Respectively, the educational level of mothers is observed to be at $50.8 \%$ (128) of intermediate educational level, 33.7\% (85) of high educational level and only $15.5 \%$ (39) of low educational level.

\subsection{Materials}

A written structured questionnaire comprised of closed-ended questions was selected as the tool for data collection and was individually completed by the students (Gymnasium and Lyceum). The questionnaire was formed for the purposes of this study (van der Vinne et al., 2014; Hirshkowitz et al., 2015) and is based on the data collection from Gymnasium - Lyceum students, in order to examine their perceptions about the time they spend within or outside school, the connection of that time to the children's biorhythm and the way this connection affects their school performance.

The questionnaire provided to the students included 22 questions. The five-point Likert scale (strongly disagree - disagree - neither agree nor disagree - agree - strongly agree) and the five-point scale with answers such as "never - rarely - sometimes - often - very often" were used. In the first section, students were asked about demographics regarding their gender, grade, whether they have siblings and if so, how many, fathers' and mothers' education, parents' professions if they have one (either one or both parents). In the next section, students were asked about their daily lives' habits, such as bedtime, diet before school, weekend habits, as well as their performances and studying after school. Subsequently, students were asked about their convenience of early awakening and whether they sufficiently manage to cope with early-hour school classes, that is, whether they perform to higher standards. In this study, students are also encouraged to indicate whether the class is boring or difficult, and to suggest ways of improvement so that the class is not boring or tiring, but pleasant, as it will include practical activities. 
The following questionnaire section concerns the time children spend outside of school and students are also asked whether extracurricular activities are beneficial to new learning acquisition.

The final three questions involve the students' disposition to manage part of their school time, the students' feelings towards their night sleep, as well as their views regarding modifications in the timetable.

\subsection{Method}

This study was conducted in Gymnasiums and Lyceums of the Prefecture of Kozani. Students who participated were in A ', B', C' Gymnasium, as well as A' Lyceum. The time frame of the research was two months (May and June 2019), and the questionnaires were distributed to the subjects by the researcher herself.

The schools' selection was based on random sampling in public secondary schools and high schools of urban areas. An identical order of questions was followed for all subjects, while from the beginning, that is, prior to the construction of the questionnaire, the researcher pointed out that there are no right or wrong answers and that the focus of this study is also on the free expression of each individual's experience.

\section{Results and Discussion}

In this section, the results will be presented according to the answers provided by the respondents. The results were calculated after the statistical analysis conducted with the program SPSS.

With regards to the students' statement about morning awakening, they were provided with five Likert scale answer options $(0=$ never, $1=$ rarely, 2 = sometimes, $3=$ often, 4 = very often), which correspond to five categories and concern the students' morning awakening, the majority appears to wake up easily in the morning (M: 2.02, SD: 1.32). In the question about morning awakening and, more specifically, whether students wake up easily in the morning, 69 students stated that sometimes (27\%) they wake up easily, 52 students often wake up easily (20.6\%), 47 students rarely wake up easily $(18.7 \%), 42$ students stated that they never wake up easily $(16.7 \%)$, while 42 students stated that they very often wake up easily in the morning $(16.7 \%)$.

The majority of the students, corresponding to $42.5 \%$, go to bed after 12 o' clock. Respectively, $36.1 \%$ of the students go to bed at $11-12$ o'clock, $17.5 \%$ of the students go to bed 10-11 o' clock, while 4\% go to bed 9-10 o'clock. The analysis indicated that there was a statistically significant relevance between the class that students attend and the time they go to bed, $x 2(2, N=252)=8.793, \mathrm{p}<.05$, Cramer $^{\prime} \mathrm{V}=.19$. We, therefore, conclude that there is relevance between the two variables.

The majority of the students, which corresponds to $46.8 \%$, wake up at $7-7: 30$ o' clock, $46.4 \%$ wake up at 7:30 - 8:00 o' clock, while 6.7\% wake up at 6:30 to 7:00 o'clock. 
The majority of the students, which corresponds to $82.5 \%$, go to bed after 12 o' clock during the weekends. Respectively, $11.9 \%$ of the students go to bed at $11-12$ o'clock, $4.4 \%$ of the students go to bed at 10-11 o'clock, while $1.2 \%$ goes to bed at 9-10 o'clock. The analysis indicated that there was a statistically significant relevance between the class students attend and the time they go to bed in the weekends, $x 2(2, N-252)=20.942$, p < .05 , Cramer' $\mathrm{V}=.17$. We, therefore, conclude that there is relevance between the two variables.

The majority of the students, which corresponds to $47.6 \%$ wakes up at $11-12$ o'clock in the weekends, $25.8 \%$ wakes up at $10-11 \mathrm{o}^{\prime}$ clock, while $17.5 \%$ wakes up at $9-10$ o' clock in the morning, $7.9 \%$ of the students wake up at $8-9$ o'clock in the weekends, $0.4 \%$ wake up at 7:30 - 8:00 o'clock, $0.4 \%$ wakes up at $7-7: 30 \mathrm{o}^{\prime}$ clock, and $0.4 \%$ of the respondents wake up at 6:30 up to 7:00 o 'clock.

As observed, $50.8 \%$ of the respondents do not have breakfast, while $49.2 \%$, almost the remaining half, do have breakfast. The students who go to school on foot constitute $54.4 \%$, while the remaining $45.6 \%$ go by some means of transport.

The analysis showed that there was a statistically significant relevance between the students' grade and the means of transport: $x 2(2, N=252)=21.382, p<.05$, Cramer' $\mathrm{V}=.29$. We, therefore, conclude that there is relevance between the two variables.

Among the students who participated in the present questionnaire, $1.2 \%$ need approximately 40 minutes to transfer from and to their school, $4 \%$ need 30 minutes to arrive to school, $6.3 \%$ need 20 minutes to transfer to and from their school, $13.9 \%$ need 15 minutes, $36.5 \%$ need 10 minutes, and, lastly, 38.1\% of the students need just 5 minutes to transfer to their school.

The analysis indicated that there was a statistically significant relevance between the grade that students attend and their transport time $x 2(2, \mathrm{~N}=252)=27.718, \mathrm{p}<.05$, Cramer' $\mathrm{V}=.19$. We, therefore, conclude that there is relevance between the two variables. With regards to the students' higher performance, it appears that $60.3 \%$ of the respondents perform better between 15:00 - 18:00, 31.7\% perform better between 18:00 21:00, while $7.9 \%$ of the respondents perform better between 21:00 - 24:00.

The majority of the students, which corresponds to $42.5 \%$ go to bed after 12 o' clock. Respectively, $36.1 \%$ of the students go to bed at $11-12$ o'clock, $17.5 \%$ of the students go to bed at $10-11$ o' clock, while $4 \%$ go to bed 9-10 o' clock.

The majority of the students, which corresponds to $46.8 \%$, wake up at $7-7: 30$ o'clock, 46.4\% wake up at 7:30 - 8:00 o'clock, while 6.7\% wake up at 6:30 - 7:00 o'clock.

The results indicated that there was a statistically significant relevance between the students who had siblings and those who did not, in relation to their bedtime, $x^{2}$ (1, $N=252)=4.06, p<.05$. Among those who had siblings, $80 \%$ stated that their bedtime is after 23:00, while merely $60 \%$ of those who did not have siblings stated that their bedtime is after 23:00.

The first questions to the respondents, concern performance indicators, that is, higher performance at school obligations and the curriculum. More specifically, the first 
question concerned whether "you can perform better at school during the first morning hours", where students responded that this happens sometimes (M: 1.65, SD: 1.15).

In a following question, students were asked whether they "perform better in mathematics/modern Greek language, during the first hours", where the average value of the students was approximately 2 (M: 1.78, SD: 1.15).

Next, students were asked whether they perform poorly due to lack of sleep. The students believe that sometimes they do (M: 2.00, SD: 1.28).

Subsequently, the parametric t-test was applied. In an attempt to examine the differences in the students' answers regarding their bedtime before and after 11, with a dependent variable "during the first morning hours I can perform more sufficiently in school", it was indicated that students who go to bed before $11(M=2.17, S D=1.26)$, believe they can perform better, compared to those who go to bed after $11(M=1.51, S D$ $=1.084)(t=2.952, d f=250, p=.358)$.

The following questions that students were asked concern indicators about time and activities within the school. More specifically, the first question concerned "I would rather interchange lessons with practical activities in school" and students responded that this is often the case (M: 2.78, SD: 1.24).

In a following question, students were asked whether they "would prefer a teaching hour to last 90 minutes" and the average of the students responded that they would rarely want this to happen (M: 0.88, SD: 1.26).

Next, students were asked whether they would like to select certain school activities and classes outside of their obligatory curriculum that would be relaxing and pleasant for them. The students would often like this to happen (M: 2.83, SD: 1.27).

Subsequently, the parametric t-test was applied. Upon examining the statistical differences, the students' responses regarding their bedtime, before and after 11 and the dependent variable "I would like to select certain school activities and classes beyond the obligatory curriculum that would be relaxing and pleasant for me", indicated that the students who go to bed prior to $11(M=2.78, S D=1.25)$ would less likely choose certain activities and classes beyond their obligatory curriculum, in comparison to those who go to bed after $11(M=2.84, S D=1.28)(t=-.335, d f=250, p=.618)$.

The next questions that students were asked concern indicators related to time spent at school and the students' daily lives. More specifically, in the first question "I would prefer the school to extend its curriculum after 14:00, as long as it provides activities that are interesting and fun", the mean value of the students did not manifest a significant desire for it $(M=1.71, S D=1.50)$.

In a subsequent question, the students were asked whether they "Would rather have lengthier school breaks, even if I finish school later, as there will be more free time to spend with my classmates" and the mean value of the students did not manifest a significant desire $(M=1.77, S D=1.51)$.

Subsequently, the dependent t-test was applied. Focusing on examining the differences among the students' responses regarding their bedtime prior and after 11 and 
the dependent variable "I would rather have lengthier school breaks, even if I finish school later, as there will be more free time to spend with my classmates" students who go to bed before $11(M=1.37, S D=1.43)$ would less likely choose certain activities and classes beyond their obligatory curriculum in relation to those who go to bed after 11 ( $M$ $=1.88, S D=1.52)(t=-2.233, d f=250, p=.0026)$.

Following, we will investigate the way the students' responses vary depending on the parents', and more specifically, the mothers' educational level. Specifically, we will examine the way that the mother's educational level (primary school, secondary school, high school, university) differentiates the students' views on whether they would rather the teaching hour to last 90 minutes.

We begin with the table with the descriptive measures of the groups (educational level = primary - secondary school, high school, university), as well as the F-test results. For the "90-minute teaching hour" factor, we will apply the non-parametric Kruskal Wallis one-way analysis of variance. The examination of Kruskal - Wallis $x^{2}$ indicated that there is a significant difference between the mothers' different educational levels, concerning whether the students would rather the teaching hour to last 90 minutes $\mathrm{x}^{2}(2$, 252) $=8.042, p=0.018$.

The Mann-Whitney U-test revealed that students whose mothers' educational level is primary - secondary school, would prefer the teaching hour to last 90 minutes (Mean Rank =151.42), compared with the students whose mothers have completed their studies in high school and would less likely prefer the teaching hour to last 90 minutes (Mean Rank=125.82) or whose mothers completed their higher education studies (Mean Rank= 116.09).

When asked whether they would prefer to select certain school activities and classes outside of their obligatory curriculum, that would be relaxing and more pleasant, students' answers reveal that the majority would very often like to implement certain activities outside of their obligatory school curriculum, that would be more pleasant, however, this rate appears to be above the mean score ( $M: 2.83, S D: 1.27$ ).

With regards to the question of whether free time outside of school helps students acquire new knowledge more effortlessly and pleasantly than the time they spend in school, their responses suggest that free time outside of school very often helps the majority of the respondents to acquire new knowledge more effortlessly and pleasantly, compared to the time they spend at school, while this rate appears to be above the mean value (M: 2.61, SD: 1.21).

With regards to the question concerning the significance of the students' extracurricular time to knowledge acquisition, $29 \%$ of the students state that extracurricular time very often helps them acquire new knowledge more effortlessly and pleasantly, $27.4 \%$ state that free time often helps them acquire new knowledge, $26.2 \%$ states that this is sometimes the case, $10.3 \%$ of the students state that free time rarely helps them acquire new knowledge, while $7.1 \%$ state that free time never helps them acquire new knowledge. The majority of the respondents appear to be in the middle of the scale, 
as the average of the respondents state that extracurricular time sometimes helps them acquire new knowledge more effortlessly and pleasantly $(M=2.61)$.

In order to investigate whether the students' gender differentiates their responses to the question whether free time outside of school helps students acquire new knowledge more effortlessly and pleasantly than the time they spend at school, the nonparametric Mann-Whitney U-test was used (the fluctuations appeared to be homogeneous, Levene's $\mathrm{p}>.081$ ). The test suggested a statistically significant difference $(\mathrm{p}<.05)$, as female students stated to a greater degree that the extracurricular activities help them acquire new knowledge more effortlessly and pleasantly $(M=2.76, S D=1.128)$, compared with the male students, who stated to a slighter degree that the extracurricular activities help them acquire new knowledge more effortlessly and pleasantly $(M=2.45$, $S D=1.271)\left(U=6460.5, z=-2.664, p=0.08\right.$. (Also, $\left.n_{1}=128, n_{2}=124\right)$.

The present results, as they emerge from the SPSS analysis, provide the Mean Rank of the two variables (Gender = male, female). The Mann - Whitney U-test suggested that females believe that free time outside of school helps them acquire new knowledge more effortlessly and pleasantly than the time they spend at school (Mean Rank=138.03), $\mathrm{U}=6460.5, \mathrm{z}=-2.66, \mathrm{n} 1=128, \mathrm{n} 2=124, \mathrm{p}=0.008$, compared to the boys (Mean Rank=114.60). Subsequently, the students were asked whether they go to bed early at night due to their parents' persistence. Out of the students total, the majority of the respondents appears to be below average, as students stated that they do not go to bed early at night, despite their parents' persistence (M: 1.21, SD: 1.27).

To the question on whether the students would like to personally manage part of their school time, the majority of the responses is above average, that is, students state that they completely agree and wish to have the ability to manage part of their school time (M: 2.81, SD: 1.04).

With regards to whether the students feel more relaxed and happier when they go to bed early on a school week, the majority of the responses is above average, as students state that they completely agree with the view according to which they feel neither calm nor happier when they go to bed early at night on a school week (M: 2.31, SD: 1.11).

Next, students were asked whether they agree with the general assumption that basic courses (Modern Greek language, mathematics, etc.) should be taught during the first hours and not the last, as students perform better in the former.

Out of the total of the students' given answers, the majority of the responses is above the mean value, as students state that they neither agree nor disagree with the view that the basic courses (modern Greek language, mathematics, etc.) should be taught during the first teaching hours and not the last, and therefore, they remain indifferent ( $M$ : 2.35, SD: 1.21).

To begin with, the descriptive elements that correspond to the factor that affects the students' performance are examined, and the mean value of each participant and the standard deviation of each factor were calculated. Specifically, students believe that they can perform better in mathematics and Modern Greek language during the first morning 
hours $(M=1.78, S D=1.146)$, and that they can perform more sufficiently at school $(M=$ $1.65, S D=1.152)$.

In order to investigate whether there is a correlation between the variables "students' performance in modern Green language and mathematics during the first teaching hours" and the factor "students' performance during the first teaching hours is more satisfactory", we applied the Pearson correlation coefficient. The correlation of the two factors, as they are presented in the above table, suggest that there is a statistically significant correlation between the students' performance during the first teaching hours and their performance in Modern Greek language and mathematics during the first teaching hours. The relation between these two variables is a positive one. A positive correlation coefficient means that the values of the two variables shift towards the same direction, that is, as the value of one factor increases, so do the values of the other. Despite the fact that there is a positive correlation coefficient between the two variables, the correlation coefficient is low, $r=0.409, p=.000$.

In the data of the present research there is the gender variable (male, female) and the variable concerning the time they wake up in the morning to go to school. Out of 252 respondents, 128 are females and 124 are males. Of the 128 females, 9 wake up to go to school between $6: 30-7(7.0 \%), 70$ females wake up between 7-7:30 (54.7\%), while 49 females wake up between 7:30 - 8:00 (38.3\%) to go to school. Respectively, out of 124 males, 8 of them wake up between $6: 30-7(6.5 \%)$ to go to school, while 68 males wake up between 7:30 - 8:00 (54.8\%) to go to school.

The analysis suggested that there is a statistically significant correlation between the students' performance in modern Greek language and mathematics, and their performance that is more satisfactory during the first teaching hours: $X^{2}(2, N=252)=$ $7.184, \mathrm{df}=2, \mathrm{p}=0.028<.05$, Cramer' $\mathrm{V}=.169$. The performance issue during the first teaching school hours appears when the male percentage that wake up earlier is lower $(38.7 \%)$, while the female percentage that wake up earlier is higher $(54.7 \%)$.

\section{Recommendations}

Several useful conclusions were drawn in the present research regarding the students' daily schedule as a significant element that affects their biorhythms. The limitations of the present study concern the sample size and its representativeness. The findings of the study should not be generalized, as the sample consists of teenage students from one regional unit of the country. Further research needs to be carried out in order to draw safe conclusions that may lead to a complete understanding of the students' time and biorhythms and the effects they might have on their school studies. Future research should focus on the biorhythms of students in all schools, as school studies and the utilization of school and non-school time are directly connected to the learning process.

It may be concluded from the results of this study that there are significant biorhythm elements that could be useful to the schedule modulation. Research such as 
the present one may contribute to the improvement of the school reality, as several school activities could be based on the desires and needs of the students.

It would be quite useful in future research to study a number of issues that students may face (such as insomnia, intense stress, stillness, palpitations, metabolic diseases, and more) and their role in school studies during a school day, as they constitute important indicators that affect the biorhythms, and, therefore, the learning process.

\section{Conclusion}

The overview of the individual findings and the preceded analysis have led to certain observations regarding the students' views, which will be presented below according to the four research questions.

The first research question investigates whether there is a relationship between the duration of sleep and the students' performance. The question concerns the sleep duration prior to and after 11 and the performance of the students. Regarding their school performance, students who go to bed prior to 11 can perform more sufficiently at school, in comparison with those who go to bed after 11.

The second research question examines whether the duration of the teaching school time affects their performances, however it does not display a statistically significant difference.

The third research question investigates whether the students' extracurricular activities are more pleasant compared to the time they spend at school. Students who go to bed after 11 believe that extracurricular activities are more pleasant in relation to the activities and time they conduct at school, compared to those who go to bed after 11 .

The fourth research question examines whether students who go to bed early exhibit higher performances in mathematics/modern Greek language: students who go to bed prior to 11 can perform more sufficiently at school, in relation to those who go to bed after 11 .

With regards to the structure and purpose of the questionnaire, it was constructed in such a way, so certain conclusions could be drawn about the students' biorhythms and the role that school and non-school time plays in learning. Thus, certain results arise regarding the effect that the students' time and biorhythms have on their activities, learning, interests, as well as their school performance.

The purpose of the first research question of this study is to examine whether there is a relationship between the duration of sleep and the students' performance. That is, whether the duration of sleep affects their preparedness and willingness during their participation in class, and, therefore, their school performances. According to the research findings, the time students go to bed (prior to or after 11), affects their preparedness and participation in class, and, therefore, their school performances, as it is evident that the time students go to bed constitutes a determining factor in order to perform sufficiently at school. Thus, the first hypothesis appears to be true. 
With regards to the "performance and timetable" section, students appear to display a negative attitude towards it, as the indicators "performances during the first teaching hours", "they present higher performances in mathematics/modern Greek language", "whether students perform poorly due to lack of sleep", have a low average, meaning that the majority does not appear to agree with the view regarding higher performances during the first teaching hours in mathematics and modern Greek language. Therefore, the second hypothesis appears to be rejected.

Regarding the second hypothesis, which examines whether the school time duration affects the students' school performances, it is observed through the students' responses that the hypothesis is true.

Students state that time during teaching hours passes slowly and is tiring, as it is suggested by the mean value of the responses, which is very low and slightly above 2 . Thus, the second hypothesis appears to be true.

In the section "time and school in the students' everyday life", the mean values are relatively low, as students seem to have a negative attitude towards it, since the indicators "time during class passes slowly and is tiring", "whether they would rather have lengthier school breaks, despite finishing school later, as there would be more free time to spend with their classmates", as well as whether "they would prefer that one teaching hour lasts 90 minutes" display a low average, that is below 2. However, it appears that students have a positive attitude towards the question on whether "they would prefer that school classes interchange with practical activities", as the average of the students' responses is close to 3.

The purpose of third research question is to examine whether there is a gap between school time and time outside of school regarding the participation and pleasure obtained by the students.

Regarding the section "time in students' everyday life", students appear to have a positive attitude towards it, as indicators such as "free time outside of school helps students acquire new knowledge more efficiently and pleasantly than the time they spend at school", as well as the indicator "whether students would prefer to manage part of their school time themselves", have an average that is close to 3. It, therefore, appears that it is confirmed that extracurricular time helps students at school, however they would much prefer to manage part of their school time themselves. Thus, the third research question is confirmed.

The purpose of the fourth research question is to examine whether their daily life schedule affects their school time performances. The results of the study indicate that students do not have a positive attitude towards the view that "when they go to bed early at night, during a school week, they feel calmer and happier", while they do not have a positive attitude towards the view that basic courses (modern Greek language, mathematics, etc.) should be taught during the first teaching hours and not the last, because students perform better, as it is shown that the average of the responses is low and, more specifically, close to 2 . Thus, it appears that the fourth hypothesis is not true. 
With regards to whether the students' activities during their free time positively affect their performances, it appears that the participants are on the average of the scale, as the respondents state that free time outside of school sometimes helps them acquire new knowledge more efficiently and pleasantly, however the responses vary depending on the gender, as females stated to a higher degree that extracurricular activities help them acquire new knowledge more efficiently and pleasantly in relation to the males.

Overall, students have a positive attitude towards preferring the teaching hour to last 90 minutes. However, depending on the level of education of the parents and, more specifically, of the mothers, it appears that the views vary. Students with mothers whose educational level is primary - secondary school, prefer the teaching hour to last 90 minutes in relation to students whose mothers have completed their higher education studies and have a more negative attitude towards the 90-minute duration of the teaching hour.

With regards to whether the students' awakening time varies according to their gender, females wake up earlier than the males.

Teenagers' biorhythms constitute biological clocks with specific cycles and functions, as the human body and, hence, that of the teenage student, is programmed to perform better in specific times during the day, compared to others. Studies have shown that there are different types of people who display a variety of habits between sleep and awakening (Kerkhof, 1985; Jones et al., 2017; Wittmann et al., 2006).

Particular importance is given to the conciseness of the body in hormones, which are predominantly melatonin and cortisol that determine the operation of the biorhythms. Melatonin is increased mainly during sleep time, in the first morning hours, while cortisol is increased after the morning awakening and during noon (Kostoglou Athanasiou, 2013).

It is additionally observed that there is correlation between the students' grade and the time they go to bed. In older grades, a significant number of students go to bed after 11.00. Thus, as teenagers sleep later, while schools impose early beginning of classes, students face issues as they are unable to adjust their circadian rhythm (Milic et al., 2014). The greatest performance of the students in relation to their duration of sleep is verified by several studies and research. The biological rhythms of the students do not allow them to go to bed early and, therefore, their performances are negatively affected. According to Gross (2014), teenagers, opposed to adults, have a biological need for more sleep, as they are still in the phase of their physical development. Similar research (Wahlstrom, 2014) finds decreased hours of sleep in teenagers and attributes them to social reasons, use of new technologies, increased amount of light and the consumption of caffeinated liquids.

The students' responses to the question regarding their performances in mathematics and Modern Greek language during the first hours, indicate a positive correlation, however they do not believe that the duration of sleep affects their performances, a fact that is not in agreement with the above findings. It should be taken 
into account that there are several factors that affect the performances, such as the environment of the classroom, the organization of the school, the students' personalities and the important role of the teaching practices applied by the teacher in the class (Joyner \& Molina, 2012).

With regards to their higher performance after school, the findings of the present study reveal that the majority of the students display better performances between 15.00 to 18.00 , meaning that during these hours, the learning process might be more effective. This conclusion is in agreement with the study which argues that the students' performance is decreased between 11:00 to 11:30am, before it is minimized at 02:00pm, while throughout the day, the biorhythms begin to increase (Kolovos, 2004).

A significant finding is the students' desire to have classes in addition to the traditionally institutional ones (mathematics, natural sciences, etc.) and, in fact, the wish to be able to select certain courses. This finding confirms the solutions that have been recorded so far. Sofou (2002) refers to choosing the idea of "flexible time", that will help students perform better in school. Other studies argue that it is necessary to establish a more flexible organization in terms of time and school schedule management that focuses on the individual spectrum of the performance and activity (Thoidis, 2000), while the implementation of sports and artistic activities would be a positive addition to the students' performance, with reference to the flexible zone, as well (Kolovos, 2004).

Equally important are the findings that extracurricular free time helps students acquire new knowledge more efficiently and pleasantly than the time they spend at school. This confirms studies which support that teachers should organize their teaching material based on real students' experience, and to additionally promote complex thinking and brain development (Vasiliou, 1987).

With regards to the means of transport, it is observed that older students (third grade of Gymnasium and first grade of Lyceum), move on foot and not with a means of transport, which is understandable, as older children move more easily on their own. In addition, the time required in order for the students to arrive to school, provides evidence regarding their place of residence and the distance in relation to the location of the school unit, without relevant bibliography. There is also no relevant bibliography that points out that students with siblings go to bed later, compared to students with no siblings. Most likely, the siblings' companion plays an inhibitory role in going to bed early.

A more efficient school time management is therefore proposed, which takes into consideration the great importance of biorhythms on the teaching practice and the educational reality. Of great importance is also the focus on the sleep duration, as well as its quality since it constitutes a significant indicator of their performance. Regarding the students' higher performances, the performance capacity increases throughout the day, therefore, the teaching of demanding courses during these hours could be scientifically substantiated. Additionally, it is proposed that special attention is given to the modification of the curriculum in relation to its general philosophy, focusing on the preferences and interests of the students, while implementing selective courses with 
cultural, social, artistic and sports content. The formation of flexible zone could be extended to the secondary education, providing students with the ability to acquire new knowledge more pleasantly and creatively. The flexible zone constitutes part of the weekly schedule. It is an educational proposition for interdisciplinary activities and more active participation of the students, as there are flexible-themed projects with the teacher's presence as coordinator and supporter. Some indicative thematic areas are sports, the environment, reading, technologies, civilization, consumer education and gender equality.

\section{About the Author(s)}

Notopoulou Vasiliki is Headmaster in the Secondary School of Xyrolimni, Kozani. She has been a research fellow at the University of Western Macedonia in the Obstetrics Faculty since 2011. She holds a PhD degree from the University of Ioannina, related to the history of Medicine and she is completed her Master degree in Innovations in Education in the School of Primary Education in University of West Macedonia, in 2020. She holds a Bachelor degree in Biology from the Aristotle University of Thessaloniki and a Bachelor degree in Business Administration from the UOWM in Grevena. She has participated and has presented projects related to her $\mathrm{PhD}$. As a research fellow in the Obstetrics Faculty at the University of Western Macedonia, her fields focus on Biology and laboratory courses in Clinical Biochemistry. She is also a research fellow in the Faculty of Occupational Therapy at the University of Western Macedonia and her field is laboratory courses in Anatomy. Additionally, she is also member of the Laboratory of the Environmental Technology.

Email: vasonot@hotmail.com

Stergiani Giaouri is an Assistant Professor of School Psychology at the University of Western Macedonia, Greece. She has graduated from the Department of Psychology, Aristotle University of Thessaloniki. She also did postgraduate studies in Social Psychiatry and Child Psychiatry at the School of Medicine in the University of Ioannina. At the University of Western Macedonia pursued doctoral study leading to doctorate in Cognitive Psychology/Special Education. She works as a research assistant in various projects of the University and as a teaching assistant in special education and school psychology courses. She has published research papers in refereed academic journals and books. www.researchgate.net/profile/Stergiani Giaouri

Email: sgiaouri@uowm.gr

\section{References}

Bailey, S., \& Heitkemper, M. (2001). Circadian Rhythmicity of Cortisol and Body Temperature: Morningness-Eveningness Effects. Chronobiology International, 18(2), 249-261. doi: 10.1081/cbi-100103189 
Buccheri, R., Saniga, M., \& Stuckey, W. (2003). The nature of time--geometry, physics, and perception. Dordrecht: Kluwer Academic Publishers.

Colclough, O., \& Crosier, D. (2014). Eurydice. Retrieved 7 March 2020, from https://webgate.ec.europa.eu/fpfis/mwikis/eurydice/index.php/

Publications:Focus on:Do children who spend more time in lessons do bette $\underline{\mathrm{r} \% 3}$

Dimitriou, A., Kiranidou, A., Kiranidou, M., Filippou, M., \& Charalabou, G. (2020, June, 20). The role of the cerebellum in the central nervous system. Brain - Archives of Neurology and Psychiatry. Retrieved from: http://www.encephalos.gr/full/45-3$\underline{01 g . h t m}$

Eisler, A., \& Eisler, H. (1992). Time perception: Effects of sex and sound intensity on scales of subjective duration. Scandinavian Journal of Psychology, 33(4), 339-358. doi: 10.1111/j.1467-9450.1992.tb00923.x

Fontana, A., Copetti, M., Mazzoccoli, G., Kypraios, T., \& Pellegrini, F. (2012). A linear mixed model approach to compare the evolution of multiple biological rhythms. Statistics in Medicine, 32(7), 1125-1135. doi: 10.1002/sim.5712

Gross, G. (2014). Sleep for Success: Why Teens Need to Start School Later. 2020, 04,07Huffpost Retrieved 7 April 2020, from http://www.huffingtonpost.com/drgail-gross/teens-sleep b 5127547.html

Hargreaves, A. et al. (1997). Racing with the clock. New York: Teacher College Press.

Hirshkowitz, M., Whiton, K., Albert, S., Alessi, C., Bruni, O., \& DonCarlos, L. (2015). National Sleep Foundation's sleep time duration recommendations: methodology and results summary. Sleep Health, 1(1), 40-43. doi: 10.1016/j.sleh.2014.12.010

Husti, A. (1992). Del tiempo escolar uniforme a la planificacion movil del tiempo. Revista

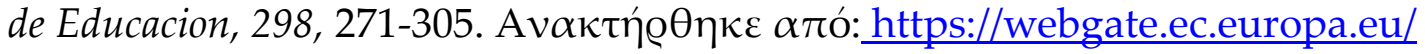

Jones, L., Harvey, B., Cochrane, L., Cantin, B., Conway, D., \& Cornforth, R. (2017). Designing the next generation of climate adaptation research for development. Regional Environmental Change, 18(1), 297-304. doi: 10.1007/s10113017-1254-x

Joyner, S., Molina, C., Beckwith, S., \& Williams, H. K. (2012). Class time and student learning. Austin, TX: Texas Comprehensive Center.

Kassaveti F. (2019, September, 09). Biological clock. Thrive global. Retrieved from: https://www.thriveglobal.gr

Kerkhof, G., 1985. Inter-individual differences in the human circadian system: A review. Biological Psychology, 20(2), 83-112.

Kolovos, St. (2004). School and Its Use: Reality and Prospects. The Educational, 73-74, 130142.

Konstantinou, H. (2015). The good school, the competent teacher and the appropriate education as tedagogical theory and practice. Athens: Gutenberg.

Kontoaggelos, K., Papageorgiou, H., Raptis, A., Tsiotra, P., Mpoutati, E., Papadimitriou, K., Dimitriadis, G., Rabavilas, A., \& Raptis, S. (2013). The role of oxytocin, cortisol, 
homocysteine, cytokines in diabetes mellitus and their interaction with psychological factors. Archives of the Hellenic Medical Society, 1, 7-22.

Kostoglou - Athanasiou If. (2013). Therapeutic advances in endocrinology and metabolism - Therapeutic applications of melatonin. (2013, February, 05). Sagejurnal. Retrieved from: https://journals.sagepub.com/doi/10.1177/2042018813476084

Kupersmidt, J. B., \& Coie, J. D. (1990). Preadolescent peer status, aggression, and school adjustment as predictors of externalizing problems in adolescence. Child Development, 61, 1350-1362.

Milić, Jakov \& Kvolik, Ana \& Ivković, Martina \& Babic Cikes, Ana \& Labak, Irena \& Benšić, Mirta \& Ilakovac, Vesna \& Zibar, Lada \& Heffer, Marija. (2014). Are there differences in students' school success, biorhythm, and daytime sleepiness depending on their school starting times? Collegium antropologicum, 38, 889-94.

Pedagogical Institute. (2003). Summary of The Organization of School Time in Compulsory Education in European Countries, Australia, Canada, USA, Japan and New Zealand. Retrieved from www.pischools.gr/download/programs/erevnes/sxolikos xronos.doc

Randler C. Volmer C. (2013, December,1). Aggression in Youhg Adults - A Matter of short Sleep a and Social getlag Social Jetlag? Pubmed, 113-3. Retrieved from: https://doi.org/10.2466/16.02.PR0.113x31z7

Shephard, R., 1984. Sleep, Biorhythms and Human Performance. Sports Medicine, 1(1), 1137.

Sofou, E. (2002). Prisoners of time: The need for flexible use of time in modern education. Educational Issues Review, 6, 223-238.

Tankova, I., Adan, A. and Buela-Casal, G., 1994. Circadian typology and individual differences. A review. Personality and Individual Differences, 16(5),671-684.

Thoidis, I. (2003). The reconnection of childhood with adult society: The catalytic role of leisure. KINITRO, 5, 35-45.

Triarchou, L. (2015). Neurobiological bases in education. Association of Greek Academic Libraries. Retrieved from: http://hdl.handle.net/11419/5167

Van der Vinne, V., Zerbini, G., Siersema, A., Pieper, A., Merrow, M., \& Hut, R. et al. (2014). Timing of Examinations Affects School Performance Differently in Early and Late Chronotypes. Journal of Biological Rhythms,30(1), 53-60. doi: $10.1177 / 0748730414564786$

Vasiliou, G. (1987). Man in the system in: Tsiantis, M., Manolopoulos, S. (Ed.). Contemporary issues of Child Psychiatry, Volume A. Athens: Kastaniotis.

Wahlstrom, K. (2014). Examining the Impact of Later High School Start Times on the Health and Academic Performance of High School Students: A Multi-Site Study. CAREI University of Minnesota.

Randler C. Volmer C. (2013, December,1). Aggression in Youhg Adults - A Matter of short Sleep and Social getlag Social Jetlag? Pubmed, 113-3. Retrieved from: 
Walberg, H., \& Tsai, S. (1983). 'Matthew' Effects in Education. American Educational Research Journal, 20(3), 359.

Whitrow, G. J. (1980). The Natural Philosophy of Time. Oxford, Clarendon Press.

Wittmann, M., Dinich, J., Merrow, M., \& Roenneberg, T. (2006). Social Jetlag: Misalignment of Biological and Social Time. Chronobiology International, 23(1-2), 497-509. 
Notopoulou Vasiliki, Giaouri Stergiani

SCHOOL ATTENDANCE AND CHILDREN'S BIORYTHMS. SECONDARY SCHOOL

STUDENTS' PERCEPTION ABOUT THEIR SCHOOL TIME, AND OUT - OF SCHOOL

TIME AND ITS RELATION TO SCHOOL ATTENDANCE

Creative Commons licensing terms

Author(s) will retain the copyright of their published articles agreeing that a Creative Commons Attribution 4.0 International License (CC BY 4.0) terms will be applied to their work. Under the terms of this license, no permission is required from the author(s) or publisher for members of the community to copy, distribute, transmit or adapt the article content, providing a proper, prominent and unambiguous attribution to the authors in a manner that makes clear that the materials are being reused under permission of a Creative Commons License. Views, opinions and conclusions expressed in this research article are views, opinions and conclusions of the author(s). Open Access Publishing Group and European Journal of Education Studies shall not be responsible or answerable for any loss, damage or liability caused in relation to/arising out of conflicts of interest, copyright violations and inappropriate or inaccurate use of any kind content related or integrated into the research work. All the published works are meeting the Open Access Publishing requirements and can be freely accessed, shared, modified, distributed and used in educational, commercial and non-commercial purposes under a Creative Commons Attribution 4.0 International License (CC BY 4.0) 